\title{
Canticum Novum. Música sem palavras e palavras sem som no pensamento de Santo Agostinho
}

\author{
LORENZO MAMMİ
}

$\mathrm{N}$

AS PRIMEIRAS páginas do diálogo De magistro, antes de iniciar uma análise minuciosa da linguagem, Agostinho exclui de sua área de indagação duas práticas que considera, de certa maneira, casos limite: o canto e a reza. Os signos lingüísticos nascem da impossibilidade de as almas humanas comunicarem-se diretamente entre si, após a queda no pecado; sua função é ensinar conceitos ou transmitir vontades. Em síntese, a linguagem é um instrumento que permite que as almas ajam uma sobre outra (1).

Nessa ótica, canto e reza não são propriamente atos lingüísticos. Cantar, quando não for uma profissão, é uma atividade que busca apenas o prazer pessoal, não a comunicação de um conteúdo específico. Por outro lado, rezar é dirigir-se a Deus, procurando um contato que dispensa a mediação dos signos. A prova de que canto e reza se situam fora da linguagem, pelo menos parcialmente, é, no caso do canto, a possibilidade de cantar sem palavras; no caso da reza, a possibilidade de cumpri-la a sós, em silêncio (2).

A prática da oração silenciosa tornou-se um hábito para o cristão da Alta Idade Média, sobretudo por causa das ordens monásticas (3). Ela encontra sua justificação em várias passagens dos Evangelhos, dos Salmos e das epístolas de São Paulo, que exortam a rezar (às vezes cantar) com o coração ou com a mente, e não apenas com a língua. Esses textos são comentados repetidas vezes pelos autores cristãos dos primeiros séculos (4). No De magistro, por exemplo, santo Agostinho cita a esse propósito $S$. Mateus, VI, 6, "Tu, porém, quando orares, entra no teu quarto, e, fechada a porta, ora a teu Pai em segredo" (5) e o Salmo IV, 5, "Falem em seus corações, e mortifiquem-se em seus aposentos" (6).

O quarto fechado é interpretado por Agostinho, metaforicamente, como espaço interior, mental (penetralia mentis). Mas qual é a natureza dessa fala interior? Ela é ainda composta de palavras? Se assim for, essas palavras silenciosas ainda estariam submetidas às regras da retórica, da gra- 
mática, da métrica? Pensamos por palavras, responde Agostinho, embora, como ele mesmo reconhece, essa tese possa ser discutida (etiamsi quisquam contendat); no pensamento, as palavras têm a função mnemotécnica de chamar à mente os conteúdos da consciência.

Embora Agostinho não o diga explicitamente, o texto parece indicar que as palavras pensadas mantêm com os significados uma relação mais forte do que a das palavras pronunciadas (7). Com efeito, os signos lingüísticos possuem, para Agostinho, uma forte opacidade: o significado deles pode ser explicado apenas por outros signos, e na verdade seriam incomprensíveis, se já não conhecêssemos seu sentido de antemão. Com as palavras não se aprende nada mais do que palavras, isto é, sinais sonoros que possuem este ou aquele significado já conhecido (8). Quando porém Jesus Cristo ensina aos discípulos uma reza, em $M t$. VI, 9, não ensina palavras, mas indica as coisas às quais o fiel deve pensar quando reza (9). As palavras da oração, portanto, enquanto palavras interiores, são apenas lembretes, indicações para operações do pensamento. Por essa via, a palavra antiga, enquanto evento sonoro concreto, começa a esvanecer. A palavra mental, símbolo de uma operação da consciência, começa a substituí-la.

A leitura silenciosa, que se difunde justamente nessa época, é uma outra faceta do mesmo fenômeno. Dessa prática, Agostinho nos proporcionou um dos testemunhos mais antigos e vivos:

“Quando [Santo Ambrósio] lia, os olhos percorriam as páginas e o coração penetrava-lhes o sentido, enquanto a voz e a língua descansavam. Nas muitas vezes em que me achei presente - porque a ninguém era proibida a entrada, nem havia o costume de lhe anunciarem quem vinha -, sempre o via ler em silêncio e nunca de outro modo.

Sentava-me e permanecia em longo silêncio - quem é que ousaria interrompê-lo em seu trabalho tão aplicado? -, afastando-me finalmente. Imaginava que, nesse curto espaço de tempo em que, livre do burburinho das questões alheias, entregava-se ao fortalecimento de sua inteligência, não queria se ocupar de mais nada. Lia em silêncio, para se precaver, talvez, contra a eventualidade de lhe ser necessário explicar a qualquer discípulo, ansioso e atento, alguma passagem que parecesse mais obscura no livro que lia, fazendo-o gastar mais tempo neste trabalho e ler menos tratados do que desejaria. Ainda que a razão mais provável de ler em silêncio pudesse ser para descansar a voz, que facilmente enrouquecia. Mas fosse qual fosse a intenção com que o fazia, sendo feita por tal homem, só poderia ser boa" (10). 
Jorge Luis Borges comentou essa passagem num ensaio: "Santo Agostinho foi discípulo de Santo Ambrósio, o bispo de Milão, até o ano 384; treze anos mais tarde, na Numídia, redigiu suas Confissões e ainda o perturbava aquele espetáculo singular: um homem na sua casa, com um livro, lendo sem articular as palavras. Aquele homem passava diretamente do signo da escrita à intuição, omitindo o signo sonoro; a estranha arte que iniciava, a arte de ler em silêncio, conduziria a maravilhosas conseqüências” (11).

A leitura silenciosa remete à meditação solitária e à oração interior. Uma história dessa práticas encontraria muito material nos escritos de Agostinho. Aqui será suficiente lembrar a meditação noturna no início do $D e$ ordine, já citada, e o exórdio dos Solilóquios: "Há muito tempo me revolvia em mil pensamentos; sim, há muitos dias procurava ardentemente a mim mesmo, buscava meu bem, o mal que deveria evitar, quando de repente ouvi uma voz: era eu mesmo? Era a voz de um estranho? Vinha de dentro ou de fora? Não sei, e todos meus esforços se concentram justamente em resolver isso (12).

Pela mediação do silêncio, paradoxalmente, a reza se aproxima ao canto. Rezar implica mergulhar em si mesmo, já que Deus habita as profundezas da alma (13); analogamente, quando cantamos para nosso prazer pessoal, nos dirigimos a nós mesmos, afastando-nos do mundo. Cantar significa abandonar-se aos próprios ritmos vitais, tomando-os não como instrumentos para a satisfação de necessidades ou desejos, mas como valores em si, expressões íntimas de uma beleza universal; rezar significa reconhecer em nós (em Deus que está em nós) a origem dessa beleza, e dialogar com ela. Em um tratado juvenil, o De musica, Agostinho exemplificara a diferença entre beleza em si e adequação a um fim (entre pulchrum e aptum) mediante a imagem de um oleiro que molda um vaso com gestos ritmados, que se tornariam uma dança, se o artesão esquecesse o objeto que está moldando (14). Da mesma forma, quem canta ou reza terá uma experiência tanto mais alta e pura quanto mais se afastar das exigências da comunicação, e portanto da linguagem.

A comunidade paleocristã conheceu uma forma de canto em que o descolamento entre música e texto é programático: o jubilus, canto sem palavras, a mais primitiva das formas melismáticas que constituirão, mais tarde, a glória e o luxo da monodia cristã. O jubilus parece ser uma conquista estética do Cristianismo. O pensamento clássico desconhece a idéia de um canto que dispense as palavras. O canto melismático também é estranho à tradição judaica, sobretudo após a destruição do segundo Templo em 70 d.C., quando, em sinal de luto, foram abolidos do culto os instrumentos e 
todas as manifestações musicais mais elaboradas. A partir de então, a música hebraica se destinou exclusivamente à leitura salmódica da Bíblia, e sua dependência do texto tornou-se absoluta (15).

O termo jubilus, que no latim da época imperial indica gritos estandardizados de soldados ou de camponeses, foi introduzido nas versões latinas da Bíblia para traduzir o hebraico terua (ou $t^{e} r \hat{u}^{c} a h$ ), tremolo ou staccato produzido pelo shofar, trombeta de chifre de carneiro. A gama sonora do shofar não ia além dos primeiros harmônicos. Sendo incapaz de escalas melódicas, o instrumento era utilizado apenas para sinais militares ou rituais. Por extensão, terua passou a indicar um grito ritmado de guerra, sendo citado nesse sentido em muitas passagens do Antigo Testamento (16). Nos Salmos, indica um grito ou uma fórmula ritual, ligada aos sacrifícios e às procissões. Seja qual for seu sentido originário, a terua deixou de ser praticada depois da diáspora (17). Ao traduzi-la por jubilus, portanto, os autores das versões latinas já não tinham experiência direta dela. Na maioria dos casos, aliás, baseavam-se na tradução grega dos Setenta, já bastante aproximada: alalagmòs. Em seu Tractatus in Psalmos, rico em notações filológicas, Hilário de Poitiers (c.315-367), observa:

"Nos manuscritos latinos se lê: Jubilate Deo omnis terra. E, no que diz respeito à nossa fala habitual, chamamos de jubilus os gritos de pastores ou agricultores quando estes, em lugares solitários, para chamar ou responder, produzem como sinal um som longo e esforçado. Mas nos livros gregos, que são mais próximos do hebraico, não se utiliza uma palavra do mesmo significado. Ali há o seguinte: alaláxate to Theó pása e gé, e com alalagmòs, que os latinos traduzem jubilus, indicam o grito do exército que combate, ou que corre atrás do inimigo em fuga, ou que festeja a vitória conseguida com gritos de aclamação. Aqui, a escolha da tradução enfraquece o sentido, como fica mais claro num outro salmo, que diz: Omnes gentes, plaudite manibus, jubilate Deo in voce exultationis (Ps. XLVI:2). Ora, o grito de aclamação [vox exultationis] é diferente do jubilus; mas na tradução, não encontrando um termo apropriado, foi utilizado jubilus para grito de aclamação" (18).

Por vox exultationis, Hilário quer dizer aqui, provavelmente, não um grito espontâneo, mas uma aclamação estandardizada. O texto inteiro, aliás, sugere fórmulas melódicas curtas, simples e provavelmente ritmadas (plandite manus, batam palmas, no segundo exemplo). Nisso, a descrição de Hilário coincide com as de outras testemunhas antigas: o jubilus primitivo parece ter sido algo parecido a um curto refrão em ritmo claro e marcado, que a assembléia inteira pudesse cantar junto com o sacerdote - bastante diferente, 
portanto, dos aleluias e das outras formas melismáticas do gregoriano, com que o jubilus costuma ser confundido. É importante manter presente esse dado, ao abordar as Enarrationes in psalmos 32 e 99 de santo Agostinho, que descrevem e comentam essa prática.

As Enarrationes (comentários) são os textos, taquigrafados e depois passados a limpo, das leituras públicas dos salmos que o santo ministrava em Hipona e em outras cidades africanas. Abrangem um período bastante amplo (de 393 a 418) (19) e, diferentemente do Tractatus de Hilário, que é um trabalho erudito, são escritos num tom simples e didático. As passagens das Enarrationes relativas ao jubilus são citadas com freqüência nas histórias da música, por duas razões: primeira, o paralelo entre o jubilus cristão e o canto de lavoura nos fornece informações preciosas tanto sobre os hábitos litúrgicos, quanto sobre o canto popular na Antigüidade tardia; segunda, o elogio explícito ao canto melismático representa uma novidade na estética musical antiga.

Esses elementos, de fato, se não são totalmente novos, são explorados por Agostinho com uma sutileza e uma profundidade que não encontra respaldo em seus predecessores. No entanto, o traço marcante desse texto, a nosso ver, é a maneira como Agostinho articula a justificação espiritual do jubilus num contexto mais amplo, transformando-a em fulcro de uma teoria estética radicalmente inovadora:

"Cantem para ele um novo canto. Deixem os velhos hábitos: aprendam um novo canto. Novo homem, novo Testamento, canto novo. O novo canto não pertence aos velhos homens; apenas os novos homens o aprendem, eles que, pela Graça, foram rejuvenescidos da velhice, e já pertencem ao novo Testamento, que é o reino dos céus. Todo nosso amor anseia por ele, e canta um novo canto. Cantem um novo canto, não com a língua, mas com a vida. Cantem para ele um novo canto: cantem bem para ele. Alguém perguntará como cantar para Deus. Cante para Ele, mas não cante mal. Não queira ofender os ouvidos dele. Cante bem, irmão. Se alguém lhe pedir para cantar, para o prazer de um bom ouvinte de música, e se você for desprovido de toda instrução na arte musical, ficará com receio de desagradar esse especialista; de fato, ele censurará falhas que você, por ignorância, nem percebe. Quem, portanto, se sentirá à altura de cantar bem para Deus, para tamanho juiz, tamanho examinador de todas as coisas, tamanho ouvinte? Quem poderá alcançar uma arte tão refinada no canto, que não desagrade em nada ouvidos tão perfeitos? 
Eis que Ele lhe dá, por assim dizer, o tom da melodia a ser cantada; não procure as palavras, como se pudesse expressar algo que agrade a Deus. Cante no jubilus. Cantar com arte para Deus consiste justamente nisso: cantar no jubilus. O que significa cantar no jubilus? Compreender e não saber explicar com palavras o que se canta com o coração. Os que cantam durante a colheita ou durante a vindima, ou num outro trabalho intenso, primeiro começam a exultar com as palavras do canto, mas em seguida, preenchidos de uma alegria que não podem mais expressar com palavras, afastam-se das sílabas das palavras e entregam-se ao som do jubilus. O som do jubilus significa que o coração dá à luz algo que não pode ser dito. E quem merece essa jubilação, senão Deus inefável? Inefável, de fato, é aquilo que não pode ser dito; e, se você não pode falar, e no entanto não deve se calar, o que resta senão jubilar, por que o coração regozije sem palavras, e a imensidão do regozijo não encontre limite nas sílabas? Cantem bem para Ele, no jubilus" (20).

"Feliz o povo que compreende [intellegit] a jubilação. Acorremos, então, para essa felicidade, compreendamos a jubilação, para que não seja pronunciada sem compreensão [sine intellectu]. Para que serviria jubilar e obedecer ao salmo que reza: A terra inteira jubile para Deus, se não compreendermos a jubilação, de forma que regozije apenas nossa voz, e não o coração? De fato é o som do coração o que se compreende com a inteligência.

Direi coisas já conhecidas: quem jubila não diz palavras, o canto é uma alegria sem palavras; a melodia, de fato, é a alegria de uma alma que se expande, o mais que puder, para expressar sentimentos, não para compreender o sentido. O homem que regozija pela própria alegria, pelas palavras que não podem ser ditas e entendidas, desafoga num canto de exultação sem palavras, de forma que por meio daquela melodia parece regozijar por algo, mas, como se fosse preenchido de uma felicidade excessiva, não pode explicar por que ele está exultando. Observem isso até naqueles que cantam coisas indecentes. Certamente, o nosso jubilus não será igual ao deles, porque nós devemos jubilar na justiça, eles jubilam na injustiça; nos na confissão, eles na confusão. Todavia, para que entendam o que estou dizendo, remontando a coisas conhecidas: jubilam sobretudo aqueles que trabalham no campo. Os ceifeiros, os vindimadores, aqueles que recolhem qualquer tipo de fruto, contentes pela abundância da colheita e alegres pela fecundidade e fertilidade da terra, cantam de alegria; e, entre cantos que declamam palavras, inserem melodias sem palavras para elevar o espírito exultante, e isso é chamado jubilatio. 
(...)

Quando jubilamos? Quando louvamos algo que não pode ser dito. (...)

Refletindo sobre todas as criaturas, que podemos nomear e enumerar, a alma se pergunta: Quem fez tudo isso? Quem o criou? Quem, junto com tudo isso, criou a própria alma? O que são essas coisas sobre as quais reflito? Quem é esse eu que reflete? Quem fez os objetos e o sujeito da reflexão? Quem é Ele? Diga-o; e, para dizêlo, pense-o. Com efeito, podemos pensar algo que talvez não possamos dizer; mas de forma alguma poderíamos dizer algo que não podemos pensar. Pense-o, portanto, antes de nomeá-lo; e, para pensá-lo, aproxime-se dEle. De fato, se quisermos olhar bem algo sobre o qual precisamos falar, aproximamo-nos dele e o observamos com atenção, para não errar olhando de longe. Mas, como observamos os corpos com os olhos, assim nós O observamos com a mente, procurando-O e vendo-O com o coração.

(...)

E quando, tornando-te semelhante a Deus, começarás a senti-Lo profundamente, enquanto a caridade crescerá em ti - porque a caridade também é Deus -, sentirás aquilo que dizias, e não dizias. Com efeito, antes de sentir, acreditavas falar de Deus; agora que começas a sentir, percebes que o que sentes não pode ser dito. E então, tendo apreendido que o que sentes não pode ser dito, te calarás, e não louvarás? Ficarás mudo de louvores a Deus, e não agradecerás àquele que quis que o conhecesses? Louvaste- $\mathrm{O}$, quando O procurava; e agora, tendo-O encontrado, te calarás? Não, em absoluto; serias ingrato. (...) Como, perguntas, louvá-Lo-ei? O pouco que posso sentir, parcialmente, em enigma, como reflexo num espelho, isso já não posso explicá-lo. Mas escute o salmo: $A$ terra inteira jubile para Deus. Se cantares o jubilus a Deus, terás compreendido a jubilação da terra inteira. Jubile para Deus; não queiras repartir sua jubilação em coisas diferentes. As outras coisas podem ser nomeadas mais tarde, de uma forma ou de outra. Mas só Ele é inefável, Aquele que, nomeando-as, fez todas as coisas. Ele falou, e fomos criados; mas nós não podemos nomeá-lo. A Palavra pela qual somos nomeados é o Filho; para que pudéssemos nomeáLo em nossa fraqueza, tornou-se fraco. Podemos encontrar uma palavra para a jubilação, mas não para a própria Palavra. Portanto: A terra inteira jubile para Deus" (21). 
O primeiro trecho começa com a exortação a um canticum novum. $\mathrm{O}$ novo canto é, aqui, a nova lei, a vida nova dos cristãos. Mas é também, concretamente, uma forma de expressão nunca ouvida antes, ou melhor: algo que sempre existiu, mas agora se reveste de novos significados. O exemplo do canto de lavoura já se encontra, entre outros, no comentário ao salmo 41 de são João Crisóstomo.

O tom, porém, é diferente:

“Em primeiro lugar é necessário dizer a razão pela qual o canto foi introduzido na nossa vida, e sobretudo por que essa profecia é pronunciada cantando. Escute, portanto a razão pela qual ela é pronunciada cantando. Deus, observando que muitos homens eram preguiçosos, não se aproximavam de boa vontade das leituras espirituais, e não toleravam o esforço necessário para isso, querendo tornar esse esforço mais agradável e querendo eliminar a sensação de cansaço, misturou à profecia uma melodia, para que todos, aliciados pela modulação do canto, entoassem hinos sacros com ânimo entusiasta. Com efeito, nada eleva a alma, e, por assim dizer, lhe dá asas, e a levanta da terra, e a liberta dos vínculos corporais, aproximando-a da sabedoria graças ao amor, e torna risonho tudo o que diz respeito a essa vida, quanto um canto melodioso e um poema divino, composto em proporções rítmicas. Sem dúvida, tanto aprazem à nossa natureza os cantos e os poemas, que até as crianças de peito, quando choram e se desesperam, acalmam-se por causa deles. As amas-de-leite as balançam no berço, para frente e para trás, e cantam-lhes alguma melodia infantil, e dessa forma fechamlhes os olhos. Com freqüência os lavradores cantam no meio-dia conduzindo os animais no jugo, e consolam-se do tédio do caminho com essas canções. E não cantam apenas os lavradores, mas também, com freqüência, os camponeses que pisam os cachos de uva na tina, os vindimadores, e aqueles que cuidam da vinha, e todos que fizerem algum outro trabalho. Os marinheiros fazem o mesmo, quando remam. As mulheres que tecem, dividindo os fios entrelaçados na roca, também cantam melodias, ou sozinhas, ou todas juntas. Assim agem mulheres, lavradores, camponeses e marujos, que em suas atividades querem aliviar o esforço com o canto, de maneira que a alma suporte mais facilmente os incômodos e as dificuldades, ouvindo poemas e cantos. Portanto, esse gênero de prazer sendo inato em nossa alma, para que os demônios não introduzissem cantos lascivos e pecaminosos, Deus opôs a eles os Salmos, que numa única composição juntassem prazer e utilidade" (22). 


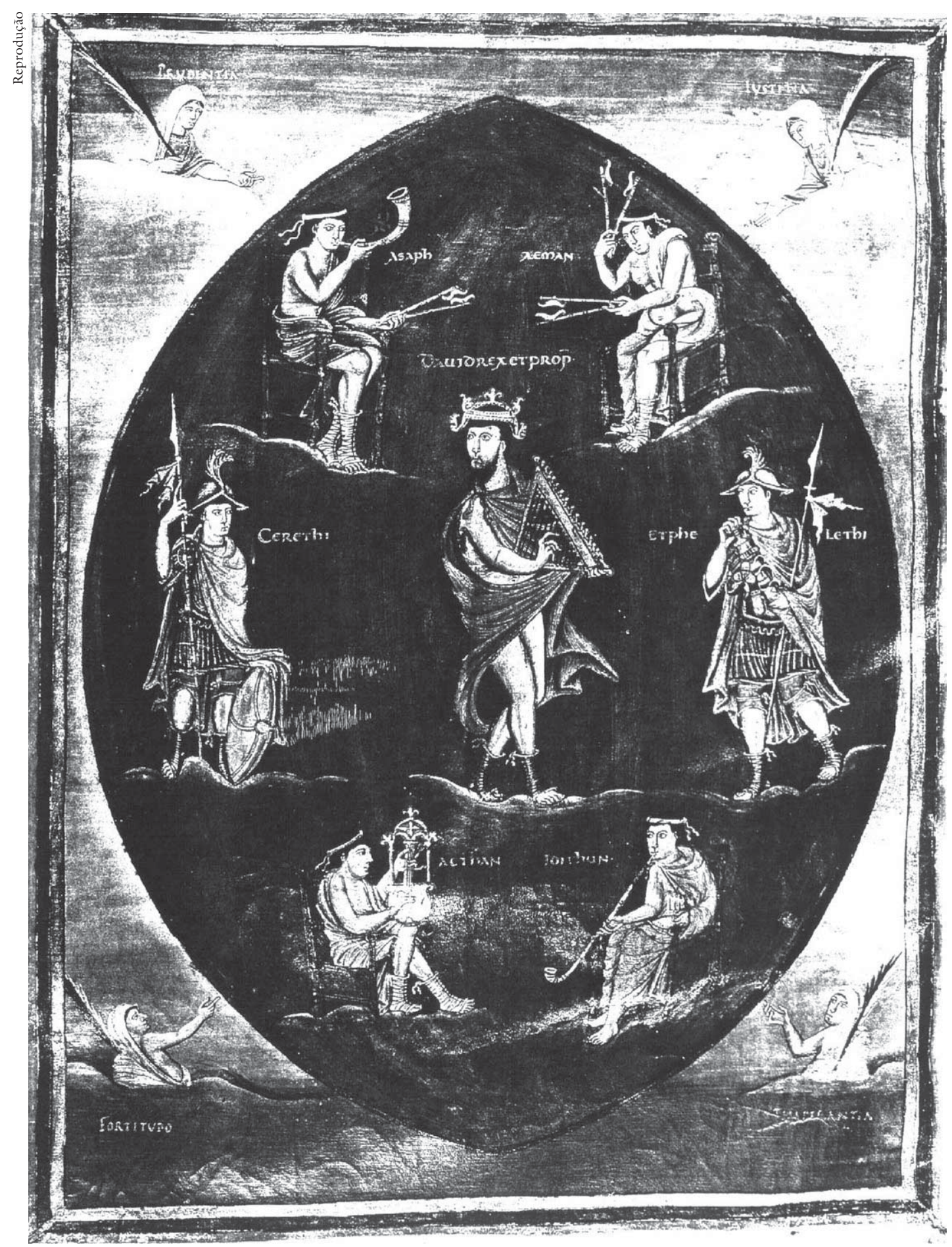

Rei David tocando harpa numa miniatura da Bíblia de Charles e Bald 
À parte semelhanças superficiais, esse texto indica uma postura oposta à de Agostinho. Para João Crisóstomo, a inclinação ao canto é uma fraqueza humana, e com ela é necessário aceitar um compromisso, para garantir a divulgação dos textos sagrados. O valor autêntico do salmo está sempre no texto. A música é apenas uma ornamentação, cuja função é tornar as palavras agradáveis para as mentes mais preguiçosas. Nesse contexto, o canto de trabalho é citado como demonstração de um instinto natural, sem qualquer conteúdo espiritual próprio. Agostinho, ao contrário, considera a linguagem um instrumento tanto mais limitado quanto mais o conteúdo a ser expresso é de natureza espiritual. Há conteúdos grandes demais para caber na linguagem humana. Nesse caso, é necessário recorrer ao jubilus, não porque este expresse aqueles conteúdos, mas porque o canto sem palavras é símbolo de nossa incapacidade para nomear Deus e, ao mesmo tempo, testemunho de que somos permeados pela palavra divina, junto com a Criação inteira. Compreender o jubilus da terra inteira significa deixar-se falar pela Palavra da Criação, renunciando a nomeá-la.

Não por acaso, o abandono do texto é descrito não apenas como renúncia a um sentido referencial, mas também como afastamento das sílabas, dos fonemas em que a fala se articula - num plano, portanto, que é puramente sonoro. Se a palavra, na leitura silenciosa e na meditação, dispensa o som ritmado e articulado e se torna pensamento puro, o som ritmado, por sua vez, acompanhando tanto o movimento corporal do trabalho quanto a experiência espiritual do êxtase, se posiciona num plano que é ao mesmo tempo pré- e pós-lingüístico. Em outras palavras, o abandono a um ritmo instintivo, fisiológico, reveste-se de uma dupla significação: no canto indecente é queda na concupiscência, rendição ao homem corporal, que está abaixo do logos, da razão; no jubilus, ao contrário, é submissão ao ritmo da Criação, renúncia à ilusão de domínio lingüístico daquilo que é indizível. O aspecto corporal da modulatio, que no De musica Agostinho afastara da ciência musical, expulsando a habilidade técnica de instrumentistas e dançarinos, é recuperado num nível mais elementar e, no entanto, mais elevado.

Talvez seja possível, sem forçar muito o pensamento de santo Agostinho, estabelecer uma hierarquia entre as formas de expressão analisadas até aqui: no vértice dos estilos literários está uma forma de sublime cristão que desarticula as construções sintáticas do latim clássico e aposta tudo na intensidade emotiva das palavras, enfileiradas na parataxe extremada que Longino classificava como assíndeto. Desse sublime, de quem procura exemplos nas Sagradas Escrituras, na verdade é ele próprio, Agostinho - o Agostinho das Confissões -, o maior representante. No entanto, acima do estilo 
sublime, há algo ainda mais alto, a expressão que, em nome da Palavra absoluta, dispensa qualquer palavra. É típico da forma mentis de Agostinho o fato que esse ponto culminante da expressão humana coincida com seu nível mais baixo e corporal. A identificação do homem com o Ser absoluto passa necessariamente pelo reconhecimento de seu não-ser, da natureza corporal que se expressa no fluxo temporal, no estar-no-tempo.

Há duas passagens das Confissões bastante significativas, nesse sentido. A primeira narra um episódio acontecido em Milão, onde Agostinho era professor de retórica:

"Como era miserável! E Tu fizeste com que eu sentisse minha desgraça no mesmo dia em que estava me preparando para pronunciar um elogio ao Imperador, em que iria dizer muitas mentiras, com a aprovação de um público consciente de que estava mentindo; e meu coração era tomado por essas preocupações e fervia pela febre de pensamentos que me consumiam. Passando por uma rua de Milão, vi um pobre mendigo, já bêbado, acredito, brincando e regozijando-se. Suspirei, e falei com os amigos que estavam comigo dos muitos sofrimentos gerados por nossas loucuras; porque com todos nossos esforços, como aqueles que me torturavam, carregando-me do peso da minha infelicidade pelo estímulo da ambição - peso que se tornava maior à medida que o carregava - não desejamos outra coisa senão alcançar aquela felicidade tranqüila, na qual este mendigo nos precedeu. E talvez nunca a conseguiremos! Porque, com poucas moedas de esmola, ele conseguiu aquilo que eu buscava por antros de sofrimentos e caminhos tortuosos, isto é, a alegria de uma felicidade temporal. Com efeito, ele não possuía uma felicidade verdadeira, mas eu, com todas minhas ambições, procurava algo muito mais falso. E, sem dúvida, ele regozijava-se, eu estava angustiado; ele era tranqüilo, eu tremia" (23).

No ápice de sua carreira oratória, Agostinho depara-se com uma figura que sintetiza a felicidade terrena: um mendigo bêbado que canta, ignorante quanto ao amanhã, mas satisfeito do seu estado presente. Evidentemente, tanto Agostinho quanto o bêbado estão, na época do encontro, no caminho errado, o caminho da concupiscência. Mas Agostinho está preparando com grande esforço seu panegírico, enquanto o bêbado se abandona a um ritmo natural, a uma felicidade animal. Ele canta para si mesmo, não para um fim instrumental. Por isso, seu canto está, paradoxalmente, mais próximo da reza - mais próximo do jubilus - do que o discurso a ser pronunciado na frente do Imperador (24). 


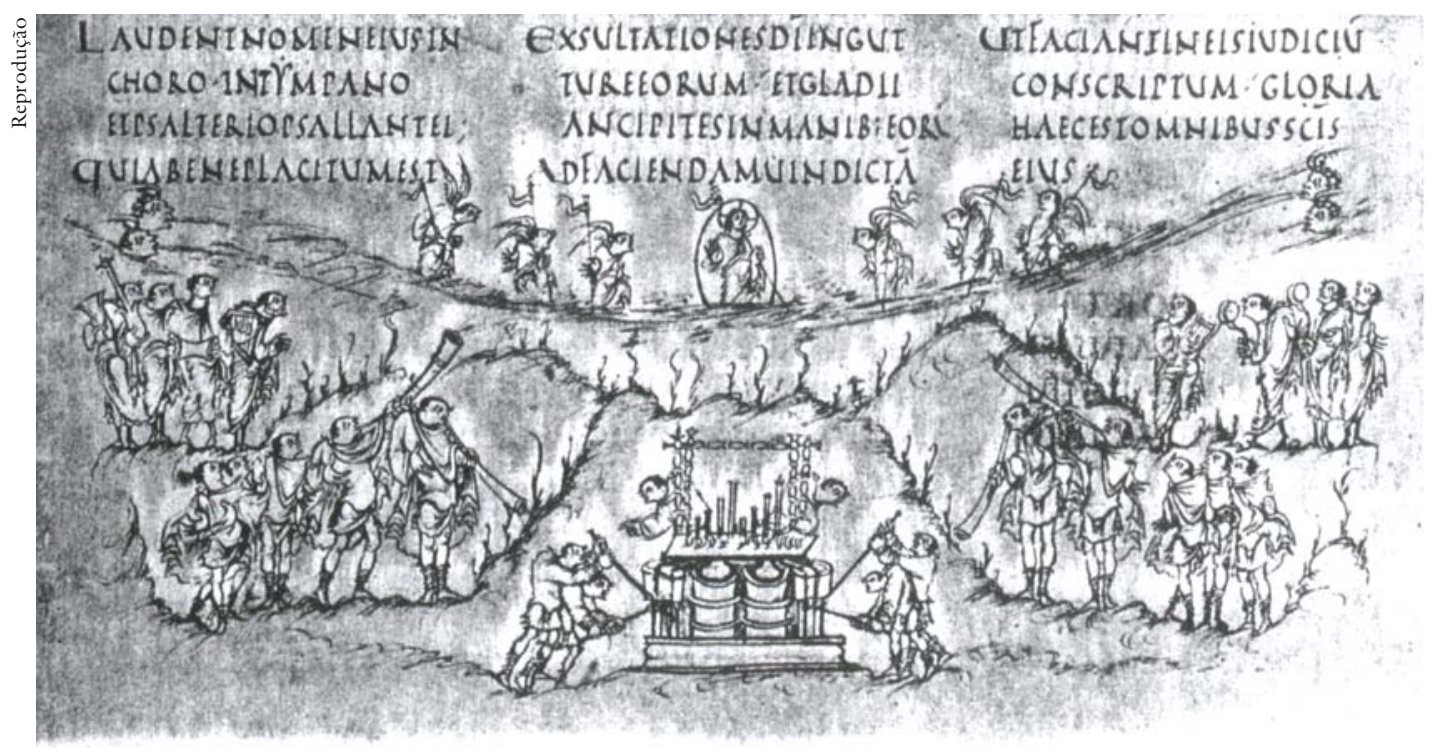

Ilustração do Salmo 150, no Saltério de Ultrechet, século IX

O segundo trecho, o episódio da morte de santa Mônica, é mais extenso. No dia da morte da mãe, Agostinho não chora. Recém-batizado, isso lhe pareceria um apego excessivo à vida terrena. Reprime as lágrimas do filho Adeodato. Canta um salmo com Euvódio, entretém discussões filosóficas. À noite toma banho, porque ouviu dizer que os banhos acalmam as inquietações do espírito. Vai dormir. Na manhã seguinte sua dor parece aliviada. Ainda deitado na cama, relembra o hino ambrosiano:

'Deus creator omnium

Polique rector vestiens

Diem decoro lumine

Noctem soporis gratia

Artus solutus ut quies

Reddat laboris usui

Mentes fessas allevet

Luctusque solvat anxios (...)" (25)

Aos poucos, voltam-lhe à mente lembranças da mãe. Começa a chorar:

"E senti prazer em chorar antes na Vossa presença por causa dela e por ela, e também por causa de mim e por mim. E deixei correr à vontade as lágrimas que reprimia, e sobre elas deitei meu coração; e este descansou nelas, porque ali estavam Vossos ouvidos, e não aqueles de um homem que interpretaria orgulhosamente meu choro" (26). 
Esse episódio desempenha um papel central na estrutura das Confissões. É com ele, em prática, que a autobiografia se interrompe: os livros seguintes serão de caráter especulativo e teológico. Mas o canto silencioso do hino não é apenas um divisor de águas. Ele parece conter a razão seminal da obra inteira: é o momento em que Agostinho descobre que não pode escapar do tempo por um esforço de abstração racional, como pregava a filosofia antiga, e que portanto a única profissão de fé possível é uma narrativa do próprio estar no tempo - uma confissão, uma autobiografia.

\section{Notas}

1 mag., I, 1-2; cf. or. II, xii, 35; mus. VI, xiii, 41.

2 mag., I, 1: "Sed nonne attendis id quod te delectat in cantu modulationem quandam esse soni; quae quoniam verbis et addi et detrahi potest, aliud est loqui, aliud est cantare?" (Não percebes que aquilo que te agrada no canto é uma certa forma sonora? As palavras podem ou não ser acrescentadas a ela; portanto, uma coisa é falar, outra cantar); mag., I, 2: "Non opus est locutione cum oramus, id est sonantibus verbis, nisi forte, sicut sacerdotes faciunt, significandae mentis suae causa, non ut Deus, sed ut homines audiant" (Para rezar não é necessário falar, ou seja emitir palavras sonoras, a não ser que façamos como os sacerdotes, que falam para comunicar seu pensamento, para que não Deus, mas os homens ouçam).

3 Cf. Rouche, 1985:517-520.

4 Cf., por exemplo, S. Atanásio, Ep. 39 ad Marcellum, Patrologia Grega XXVII, 39: "Quem portanto declamar um salmo sobre uma melodia, não faça isso pelo desejo de uma música suave, mas como signo de harmonia dos pensamentos da alma"; S. João Crisóstomo, In Ps. 41, 1, Patrologia Grega LV, 156: "O que significa $e \mathrm{~m}$ vossos corações?" ( $E f$. $\mathrm{V}, 18$-19) "Com a inteligência, responde [o Apóstolo]: as palavras não sejam pronunciadas pela boca, mas a própria mente se exteriorize e se expanda em todas as direções; para que se ouça como uma língua da alma"; no VI século, o bispo Niceta de Reims ainda bate na mesma tecla (De psalmodiae bono, Patrologia Latina LXVIII, 374): “Assim exorta o salmo, dizendo: cantem com sabedoria, porque Deus é o rei da terra inteira (Ps. XLVI, 8), "isto é: com a inteligência, para que cantemos não apenas com o sopro, isto é, com o som da voz, mas também com a mente".

5 Tradução das Edições Paulinas, São Paulo, 1985. Agostinho não cita a passagem por extenso, lembrando apenas que "nobis praeceptum esse ut in clausis cubiculus oremus" (nos foi prescrito que rezemos em quartos fechados). Essa citação, como a seguinte, está em mag., II, 2. 
6 "Dicite in cordibus vestris, et in cubiculibus vestris compungimini". Essa citação, como a anterior, está em mag., II, 2.

7 Cf. en. in Ps. 99, citado mais adiante: "Podemos pensar algo que talvez não possamos dizer; mas de forma alguma poderíamos dizer algo que não possamos pensar".

8 mag. XI, 36: "Verbis igitur nisi verba non discimus, imo sonitum strepitumque verborum" (com as palavras não aprendemos nada mais que palavras, ou melhor, o som e o barulho delas). O contraste entre a intuição imediata das coisas e o strepitum vocis é sublinhado também no famoso episódio do êxtase de Óstia, em conf. IX, x (v. pf. 3. 3. 3).

9 mag., I, 2: "non enim verba, sed res ipsas eos verbis docuit, quibus et seipsi commonefacerent, a quo, et quid esset orandum, cum in penetralibus, ut dictum est, mentis orarent" (não ensinou as palavras, mas as próprias coisas, para que eles próprios lembrassem para que e o que deve ser rezado, quando rezarem, como dissemos, na profundeza de suas mentes). Em conf. X, ix, Agostinho afirma que o conteúdo sensível da memória é composto por imagens (vestigia) das sensações, mas que as verdades intelegíveis estão nela em si, e não por imagens.

10 conf., VI, iii: "Sed cum legebat, oculi ducebantur per paginas et cor intellectum rimabatur, vox autem et lingua quiescebant. Saepe cum adessemus (non enim vetabatur quisquam ingredi, aut ei venientem nuntiari mos erat), sic eum legentem vidimus tacite, et aliter nunquam. Sedentesque in diuturno silentio (quis enim tam intento esse oneri auderet?) discedebamus, et conjectabamus eum parvo illo tempore, quod reparandae menti suae nanciscebatur, feriatum ab strepitu causarum alienarum, nolle in aliud avocari: et cavere fortasse, ne auditore suspenso, et intento, si qua obscurius posuisset ille quem legeret, etiam exponere necesse esset: aut de aliquibus difficilioribus disceptare quaestionibus, atque huic operi temporibus impensis, minus quam vellet voluminum evolveret: quamquam et causa servandae vocis, quae illi facillime obtundebatur, poterat esse justior tacite legendi. Quolibet tamen animo id ageret, bono utique ille vir agebat".

11 J.L Borges, Del culto de los libros, em Prosa Completa, Barcelona, Bruguera 1980, II: 231; or. em Otras Inquisiciones, 1952. No que diz respeito à retórica, a passagem de uma produção destinada à declamação para uma destinada à escrita (e portanto da eloqüência à literatura, no sentido etimológico dos termos), é sublinhada por Marrou, 1938: 89.

12 sol. I, i, l. A voz é da própria razão, interlocutor ideal num diálogo que é na verdade, como o título indica, um solilóquio. A aparição de uma personagem alegórica, que interrompe as meditações silenciosas, se tornou mais tarde um protótipo literário (acrescentando de costume elementos visuais, ausentes em 
Agostinho). Veja-se por exemplo o início do De consolatione philosophiae de Boécio: "Haec dum mecum tacitus ipse reputarem querimoniamque lacrimabilem stili officio signarem, astitisse mihi supra verticem visa est mulier ..." (Enquanto meditava em mim mesmo silenciosamente, escrevendo uma lamentação lacrimosa, vi uma mulher [a Filosofia] pairando acima da minha cabeça ...). Fechando o círculo, no Secretum de Petrarca (1342-1358), quem aparece ao poeta é o próprio Agostinho, acompanhado por uma mulher muda, a Verdade.

13 Em mag., I, 2, Agostinho cita a esse respeito São Paulo: "Não sabeis que sois o templo de Deus, e que o espírito de Deus mora em vós?" (I Cor. III, 16) e "Cristo habita o interior do homem" (Ef. III, 16).

14 mus., I, ii, 3. Lembramos que De pulchro et apto é o título do primeiro tratado de Santo Agostinho, escrito ainda sob a influência maniquéia. O tratado, citado nas Confissões, está hoje perdido. Para suas possíveis repercussões em textos posteriores, cf. Fontanier, 1989.

15 v. Fubini, 1994, cap. III-IV

16 Ravasi (1992:87) conta 36 recorrências desse significado do termo no Antigo Testamento. No episódio da conquista de Jericó, o grito de guerra é sempre acompanhado pelo som das trombetas (Jos VI:5, 10, 16 etc.)

17 v. Cattin, 1979: 13-14; Idelsom 1929, parte I, cap. I-III.

18 Tractatus in Psalmum LXV, 3: "In latinis codicibus ita legimus: Jubilate Deo omnis terra. Et quantum ad eloquii nostri consuetudinem pertinet, jubilum pastoralis agrestisque vocis sonum nuncupamus, cum in solitudinibus aut respondens aut requirens, per significantiam ductae in longum et expressae in nusum sonus vocis auditur. In graecis vero libris, qui ex hebreaeo proximi sunt, non eadem significantia scribitur. Namque ita se habent: alaláxate tõ the $\tilde{0}$ pãsa he gê, et cum illis alalagmòs, quem latine jubilum ponunt, significat vocem exercitus praeliantis, aut in concursu proterentis hostem, aut successum victoriae exultationis voce testantis. Quam rem ubi ita se translationis ratio temperavit, absolutius in psalmo altero intelligimus, cum dicit: Omnes gentes, plaudite manibus, jubilate Deo in voce exultationis" (Ps. XLVI:2). Vox autem exsultationis dissentit ab jubilo; sed pro translationis conditione, quia propria exsultantis vocis nuncupatio non reperta est, per id quod jubilum dicitur, vox exsultantis ostenditur". Minha tradução difere em alguns detalhes daquela inglesa em McKinnon, 1989:273, mas o sentido geral é o mesmo. As observações filológicas de Hilário têm a função de justificar sua interpretação dos salmos como instrumentos de luta contra os demônios (ibid., 4). Em defesa dos tradutores latinos, lembramos que Amiano Marcelino, historiador contemporâneo de Hilário, usa jubilatio no sentido de grito militar (v. Calonghi, Dizionario Latino-Italiano, Turim, Bona, 1967). 
19 Segundo a tabela cronológica do Corpus Christianorum (v. XXXVIII), os dois comentários em questão foram pronunciados em 403 (In Ps. 32) e 412 (In Ps. 99).

20 in Ps. 32, ii, sermão I, 8: "Cantate ei canticum novum. Exuite vetustatem: nostis canticum novum. Novus homo, novum Testamentum, novum canticum. Non pertinet novum canticum ad homines veteres; non illud discunt nisi homines novi, renovati per gratiam ex vetustate, et pertinentes iam ad Testamentum novum, quod est regnum caelorum. Ei suspirat omnis amor noster, et cantat canticum novum. Cantet canticum novum, non lingua, sed vita. Cantate ei canticum novum: bene cantate ei. Quaerit unusquisque quomodo cantet Deo. Canta illi, sed noli male. Non vult offendi aures suas. Bene canta, frater. Si alicui bono auditori musico, quando tibi dicitur: Canta ut placeas ei, sine aliqua instructione musicae atis cantare trepidas, ne displiceas artifici; quia quod in te imperitus non agnoscit, artifex reprehendit; quis offerat Deo bene cantare, sic iudicanti de cantor, sic examinanti omnia, sic audienti? Quando potes afferre tam elegans artificium cantandi, ut tam perfectis auribus in nullo displiceas? Ecce veluti modum cantandi dat tibi; noli quaerere verba, quasi explicare possis unde Deus delectatur. In jubilatione cane. Hoc est enim bene canere Deo, in iubilatione cantare. Quid est in iubilatione canere? Intellegere, verbis explicare non posse quod canitur corde. Etenim illi qui cantant, sive in messe, sive in vinea, sive in aliquo opere ferventi, cum coeperint in verbis canticorum exsultare laetitia, veluti impleti tanta laetitia, ut eam verbis explicare non possint, avertunt se a syllabis verborum, et eunt in sonum iubilationis. Iubilum sonus quidam est significans cor parturire quod dicere non potest. Et quem decet ista iubilatio, nisi ineffabilem Deum? Ineffabilis enim est, quem fari non potes; et si eum fari non potes, et tacere non debes, quid restat nisi ut iubiles, ut gaudeat cor sine verbis, et immensa latitudo gaudiorum metas non habeat syllabarum? Bene cantate ei in iubilatione".

21 in Ps. 99, 3-6: Beatus populus qui intelligit inbilationem (Ps. 88, 16). "Curramus ergo ad hanc beatitudinem, intelligamus iubilationem, non eam sine intellectu fundamus. Quid opus est iubilare et obtemperare huic psalmo dicenti: Iubilate Deo, omnis terra, et non intelligere iubilationem, ut vox nostra sola iubilet et cor non iubilet? Sonus enim cordis intellectus est. Quod nostis dicturus sum. Qui jubilat, non verba dicit, sed sonus quidam est laetitiae sine verbis; vox est enim animi diffusi laetitia, quantum potest, esprimentis affectum, non sensum comprehendentis. Gaudens homo in exsultatione sua, ex verbis quibusdam quae non possunt dici et intellegi, erumpit in vocem quandam exultationis sine verbis; ita ut appareat eum ipsa voce gaudere quidem, sed quasi repletum nimio gaudio, non posse verbis explicare quod gaudet. Animadvertite hoc in eis qui cantant etiam non honeste. Non enim talis erit jubilatio nostra, qualis illorum est; nos enim in iustificatione iubilare debemus, illi autem iubilant in iniquitate; itaque nos in confessione, illi in confusione. Tamen ut hoc quod dico intelligatis, immo recordemini rem cognitam, maxime iubilant quid aliquid in agris operantur; copia fructuum iucundati vel messores, vel vindemiatores, vel aliquos 
fructus metentes, et in ipsa fecunditate terrae et feracitate gaudentes, exultando cantant; et inter cantica quae verbis enuntiant, inserunt voces quasdam sine verbis in elatione exsultantis animi, et haec vocatur iubilatio. (...) Quando ergo nos iubilamus? Quando laudamus quod dici non potest. (...) In hac tota consideratione creaturae, quam nominare utcumque et percurrere potuimus, interroget se anima: Quis fecit haec omnia? quis creavit haec? quis in teipsam? quid sint ista quae consideras? quid tu quae consideras? quis ille qui fecit consideranda et considerantem? quis est iste? Dic illum; ut dicas illum, cogita illum. Potes enim aliquid cogitare, et forte non potes dicere; nullo modo autem poteris dicere quod non poteris cogitare. Ergo cogita illum priusquam dicas illum; ut cogites illum., accede ad illum. Quod enim vis bene videre, ut habeas quod loquaris, accedis ut inspicias, ne forte longe videndo fallaris. Sed ut oculis ista corpora, sic ille mente conspicitur, corde atenditur et videtur. (...) Et cum accedere coeperis similis, et persentiscere Deum, quantum in te caritas crescit, quia et caritas Deus est, senties quiddam quod dicebas, et non dicebas. Ante enim quam sentires, dicere te putabas Deum: incipis sentire, et ibi sentis dici non posse quod sentis. Cum autem ibi didiceris dici non posse quod sentis, tacebis, non laudabis? Ergo mutus eris in laudibus Dei, et gratiarum actionem non reddes ei qui voluit se notum tibi facere? Laudabas, cum quaereres; silebis, cum inveneris? Nullo pacto: non eris ingratus. (...) Quomodo, inquis, laudabo? Modicum ipsum quod sentire possum ex parte in aenigmate per speculum, iam explicare non possum. Audi ergo psalmum: Iubilate Domino, omnis terra. Intellexisti iubilationem omnis terrae, si iubilas Domino. Domino iubila; noli iubilationem tuam in alias atque alias res dividere. Postremo caetera dici possunt utcumque; ille solus est ineffabilis, qui dixit, et facta sunt omnia. Dixit, et facti sumus: sed nos eum dicere non possumus. Verbum eius quo dicti sumus, Filius eius est; ut a nobis utcumque possumus dicere, verbum pro verbo non possumus. Iubilate ergo Domino, omnis terra".

22 In Ps. 41, Patrologia Grega LV, 156. É possível que Agostinho conhecesse a obra de João Crisóstomo em tradução latina; cf. comunicação de M. Chirat, Revue d' Etudes Latines XXXIII [1955], 76-77.

23 conf. VI, vi, 1-2: "Quam ergo miser eram! et quomodo egisti, ut sentirem miseriam meam die illo, quo cum pararem recitare Imperatori laudes, quibus plura mentirer, et mentienti faveretur ab scientibus: easque curas anhelaret cor meum et cogitationium tabificarum febribus aestuaret: transens per quemdam vicum Mediolanensem, animadverti pauperem mendicum, jam credo saturum, jocantem atque laetantem: et ingemui, et locutus sum cum amicis qui mecum erant, multos dolores insaniarum nostrarum: quia omnibus talis conatibus nostris (qualibus tunc laborabam, sub stimulis cupiditatum trahens infelicitatis meae sarcinam, et trahendo exaggerans) nihil vellemus aliud, nisi ad securam laetitiam pervenire, quo nos mendicus ille iam praecessisset, nunquam illuc fortasse venturos! Quod enim jam ille pauculis, et emendicatis nummulis adeptus erat ad hoc ego tam aerumnosis anfractibus et circuitibus ambiebam, ad laetitiam 
scilicet temporalis felicitatis. Non enim verum gaudium habebat, sed et ego illis ambitionibus multo falsius quaerebam. Et certe ille laetabatur, ego anxius eram; securus ille, ego trepidus".

24 A imagem do canto do bêbado será retomada, como vimos, no comentário ao salmo 99. A fonte desse topos é provavelmente são Paulo, $E f .$, v, 18-19: "E não vos embriagueis com vinho, mas enchei-vos do Espírito Santo, falando entre vós com salmos e hinos e canções espirituais, cantando e salmodiando ao Senhor em vossos corações".

25 "Deus criador de tudo/Que reges o céu, que vestes/O dia de bela luz/A noite da dádiva do sono/Para que o repouso reconstrua/Os membros amolecidos pelo cansaço,/Alivie as mentes prostradas,/Dissolva os lutos tormentosos (...)

26 conf., IX, xii: "Et libuit flere in cospectu tuo de illa et pro illa, de me et pro me. Et dimisi lacrymas quas continebam, ut effluerent quantum vellent, substernens eas cordi meo, et requievi in eis: quoniam ibi erant aures tuae, non cujusquam hominis superbe interpretantis ploratum meum".

Referências bibliográficas

\section{Fontes diretas}

AGOSTINHO, Aurélio. Confessionum libri XIII (conf.), Turim, SEI, 1949; trad: J.O. Santos e A.A. de Pena. Porto, Apostolado da Imprensa, 1984; P. de Labriolle, Paris, Les Belles Lettres, 1926; E.B. Pousey, Great Books of the Western World,18, Chicago-Londres-Toronto, Enciclopaedia Britannica, 1952, p. 1-125.

. Enarrationes in Psalmos (en. In Ps.), Patrologia Latina XXXVI e XXXVII, CC XXXVIII-XXXIX.

De magistro liber; (mag.), edição bilíngüe latim-italiano (trad.

A. Cantelli), Milão, Mursia, 1993.

De musica libri sex (mus.), Patrologia Latina XXXII, col. 1081-

1194; trad.: R. C. Taliaferro, em The Father of the Church, v. IV, New York, 1947 (1. VI tb. Em Lippman, 1986); J. Thonnard, em Bibliothèque Augustinienne, v. VII, Paris, Desclée de Brouwer, 1947; M. Bettetini, em Ordine, musica, bellezza, Milano, Rusconi, 1992.

De ordine libri duo (or.), CC, Series Latina, v. XXIX, Turnholt, Brepols, 1970; trad.: V. Capanaga, em Obras de San Augustin, I, Madrid, Biblioteca de Autores Cristianos, 1979; M. Bettetini, em Ordine, musica, bellezza, Milano, Rusconi, 1992; R. Jolivet, em Saint Augustin, Dialogues philosophiques, Bruges, Desclée de Brouwer, 1955.

Soliloquiorum libri II (sol.), Patrologia Latina XXXII, c. 869- 
904; trad. fr. P. de Labriolle, em Saint Augustin, Dialogues philosophiques, Paris, Desclée De Brouwer, 1955.

POITIERS, Hilário de. Tractatus in Psalmum 65, in Ps. 65 PL IX, col. 423-436.

Fontes indiretas

CATTIN, G. Il Medioevo I (1979) v.. I/2 de Storia della Musica. Società Italiana di Musicologia, Turim, EDT, 1981.

FONTANIER, J. M. Sur le traité d'Augustin De pulchro et apto: convenance, beauté et adaptation, RSPT LXXIII, 1989, p. 413-421.

FUBINI, E. La musica nella tradizione ebraica, Turim, Einaudi, 1994.

IDELSOHN, A.Z. Storia della musica ebraica. Firenze, Giuntina, 1994 (título original: Jewish music in its historical development, 1929).

MARrOU, H.-I. (1938) Saint Augustin et la fin de la culture antique. Paris, Boccard, 1949.

McKINNON, J. (ed.). Music in early Christian Literature. Cambridge, Cambridge University Press, 1989.

RAVASI, G. Cantate a Dio con arte. Il teologico e il musicale nella Bibbia. MB, 1992, p. 65-110.

ROUCHE, M. Alta Idade Média ocidental. Em: História da vida privada, I: Do Império Romano ao ano mil. São Paulo, Companhia das Letras, 1990 (título original Histoire de la vie privée, vol. I: De l' Empire Romain à l' an mil, 1985).

RESUMO - NO De Magistro, Santo Agostinho coloca a reza e o canto numa posição similar, à margem das funções imediatamente comunicativas da linguagem. A reflexão agostiniana sobre a reza se baseia nos hábitos cristãos da leitura, da oração e da meditação silenciosas. Há sobre o canto, na prática igualmente inovadora do jubilus, melodia sem palavra destinada aos momentos mais intensos e gaudiosos da liturgia. A oração silenciosa e o jubilus são temas recorrentes da literatura patrística, mas Agostinho os aborda de maneira original, desenhando, a partir das palavras sem som da oração e do som sem palavra do jubilus, o perfil de um discurso interior, que não se destina aos homens, mas a Deus.

ABSTRACT - IN HIS De Magistro Saint Augustine places prayer and song on a similar level, alongside the language immediately communicative functions. His considerations on prayer are grounded on the Christian habits of silent reading, prayer and meditation; those on song, on the equally innovating practice called 
jubilus, which is melody without words designed for the intensest and most joyous liturgical moments. Silent prayer and jubilus are recurring topics in patristic literature, but Augustine deals with them in an original way, drawing from the soundless words of prayer and the wordless sound of jubilus an inner discourse, addressed not to men but to God.

Lorenzo Mammi, crítico de arte, é professor do Departamento de Música da Escola de Comunicações e Artes da USP.

O texto é parte da tese Santo Agostinho, o tempo e a música, defendida pelo autor na Faculdade de Filosofia, Letras e Ciências Humanas da Universidade de São Paulo em março de 1998. 